\title{
Corrosion, haemocompatibility and bacterial adhesion behaviour of TiZrN-coated 316L SS for bioimplants
}

\author{
GOBI SARAVANAN KALIARAJ ${ }^{1}$, VINITA VISHWAKARMA, ${ }^{1, *}$, \\ ANANTHAKUMAR RAMADOSS ${ }^{2}$, D RAMACHANDRAN ${ }^{1}$ and ARUL MAXIMUS RABEL ${ }^{1}$ \\ ${ }^{1}$ Centre for Nanoscience and Nanotechnology, Sathyabama University, Chennai 600 119, Tamil Nadu, India \\ ${ }^{2}$ Nanomaterials and System Lab, Science and Engineering College, Jeju National University, Jeju 690-756, \\ Republic of Korea
}

MS received 2 February 2015; accepted 17 March 2015

\begin{abstract}
TiZrN coating was deposited on 316L stainless steel (SS) by the reactive magnetron co-sputtering technique. Cubic phase of TiZrN with uniform surface morphology was observed by X-ray diffraction and atomic force microscopy. Bacterial adhesion, haemocompatibility and corrosion behaviour of TiZrN coating were examined in order to evaluate the coating's compatibility for ideal implant. Results revealed that TiZrN coatings exhibited less bacterial attachment against Staphylococcus aureus and Escherichia coli bacteria, negligible platelets activation and superior corrosion resistance than the uncoated $316 \mathrm{~L} \mathrm{SS.}$
\end{abstract}

Keywords. Biomaterials; sputtering; adhesion; corrosion.

\section{Introduction}

Biomedical implants breathe a new life to fractured bone ligaments, dental implants, cardiovascular stents and femoral implants. These implants are prone to corrosion and bacterial adhesion. To address this issue, $316 \mathrm{~L}$ stainless steel (SS) grade material is used to replace various parts of the body owing to its corrosion resistance, wear resistance and high hardness. However, after implantation, it undergoes high risk of bacterial invasion and corrosion susceptibility due to its surface chemistry. ${ }^{1}$ Hence, long-term implant survival is of critical importance for its success. Recently, transition metal nitride coatings have been taken into consideration in order to enhance substrate material properties. $\mathrm{ZrN}$ and TiN attracted much attention owing to good corrosion resistance, ${ }^{2-4}$ better mechanical properties and biocompatibility. ${ }^{5}$ However, single layer film is not very effective for practical use. Ternary nitride coatings such as $\mathrm{TiCrN}$, TiAlN ${ }^{6}$ and TiZrN possess superior properties in hardness, corrosion resistance, oxidation resistance, better compatibility due to their respective alloying effects which has been observed for the past few decades. Hence, much research has been carried out on the ternary TiZrN films ${ }^{7}$ to enhance the mechanical, corrosion resistance and biocompatibility nature. Although TiZrNbased ternary nitrides are near ideal biomaterials, their use is not guaranteed for long-term implant application due to bacterial invasion, implant corrosion and haemocompatibility nature. Hence the present work, we investigated TiZrN

\footnotetext{
*Author for correspondence (vinitavishwakarma1@gmail.com)
}

coating deposition by reactive magnetron co-sputtering on $316 \mathrm{~L}$ SS and evaluated their bacterial attachment behaviour against Staphylococcus aureus (Gram $(+) v e)$ and Escherichia coli (Gram (-)ve). Furthermore, haemocompatibility and corrosion behaviour were also evaluated and discussed.

\section{Experimental}

\subsection{Deposition and characterization of TiZrN coating}

Medical grade 316L SS was used as a substrate material. Substrates were polished using $2.5 \mu \mathrm{m}$ diamond powder followed by ultrasonication, before mounting into the vacuum chamber. TiZrN coating was deposited by reactive magnetron co-sputtering using high purity $(99.99 \%)$ titanium (Ti) and zirconium $(\mathrm{Zr})$ target in argon $(\mathrm{Ar})$ and nitrogen $\left(\mathrm{N}_{2}\right)$ gas environment. The target to substrate distance was kept at $50 \mathrm{~mm}$. The base and operating pressure in the deposition chamber was in the order of $10^{-4}$ and $4 \times 10^{-1} \mathrm{~Pa}$, respectively. Substrate temperature was $400^{\circ} \mathrm{C}$ during deposition. Glancing incidence X-ray diffraction (GIXRD) was used to characterize the deposited film using a Rigaku (Smart Lab 9KW) diffractometer using a $\mathrm{CuK} \alpha=1.5406 \AA$ radiation source. Surface topography of the samples were analysed by atomic force microscopy (AFM) using SLOVER PRO, multimode scanning probe microscope manufactured by M/s NTMDT, the Netherlands. Cross-sectional analysis was done by scanning electron microscopy (Carl Zeiss, Germany). 


\subsection{Evaluation of bacterial adhesion}

Pure cultures of $S$. aureus (MTCC no. 3160) and E. coli (MTCC no. 443) bacterial strains were brought from the Microbial Type Collection Centre (MTCC) of the Institute of Microbial Technology, Chandigarh. The cultures were maintained in nutrient broth at $37^{\circ} \mathrm{C}$ for $12 \mathrm{~h}$ as recommended by MTCC. Overnight inoculum was transferred to $20 \mathrm{ml}$ nutrient broth and incubated in a shaking incubator for $3 \mathrm{~h}$ at $37^{\circ} \mathrm{C}$ with $110 \mathrm{rpm}$. It was then adjusted to an optical density (Corning colourimeter 253 at $660 \mathrm{~nm}$ ) of between 0.1 and 0.3 which was nearly equivalent to a concentration of $2.5 \times 10^{8}$ colony-forming units per millilitre $\left(\mathrm{cfu} \mathrm{ml}^{-1}\right)$. One millimetre was then diluted 3 fold to obtain an approximate target concentration of between $1 \times 10^{5}$ and $3 \times 10^{5} \mathrm{cfu} \mathrm{ml}^{-1}$.

\subsection{Bacterial attachment of uncoated 316L SS and TiZrN coating}

Test samples were sterilized under UV lamp for $10 \mathrm{~min}$. The diluted bacterial cultures were inoculated into nutrient broth containing test samples and incubated for $24 \mathrm{~h}$. Then, the samples were washed, scrapped by a sterile brush and finally collected in phosphate-buffered saline (PBS) solution constituting $\mathrm{NaCl} 8.0, \mathrm{Na}_{2} \mathrm{HPO}_{4} \cdot 12 \mathrm{H}_{2} \mathrm{O} 2.08, \mathrm{KCl} 0.20, \mathrm{KH}_{2} \mathrm{PO}_{4}$ $0.20\left(\mathrm{~g} \mathrm{l}^{-1}\right)$ for serial dilution. Diluted samples were poured into nutrient agar plates and incubated at $37^{\circ} \mathrm{C}$ for $24 \mathrm{~h}$. The bacterial population was expressed as colony-forming units per square centimetre $\left(\mathrm{cfu} \mathrm{cm}^{-2}\right)$.

For live/dead cell analysis, same set of samples were treated with acridine orange $(\mathrm{AO})$ stain and observed using epifluorescence microscope (Nikon Eclipse E600).

Microbial efficiency of TiZrN thin films were calculated as follows:

$$
R=(B-A) / \mathrm{B} \times 100(\%),
$$

where ' $R$ ' is the reduction of survival rate, ' $B$ ' the total number of cells adhered on the surface and ' $A$ ' the cells which emit orange fluorescence.

\subsection{Platelet adhesion studies}

Platelets adhesion test was carried out to evaluate the materials thrombogenicity. The blood was drained from healthy
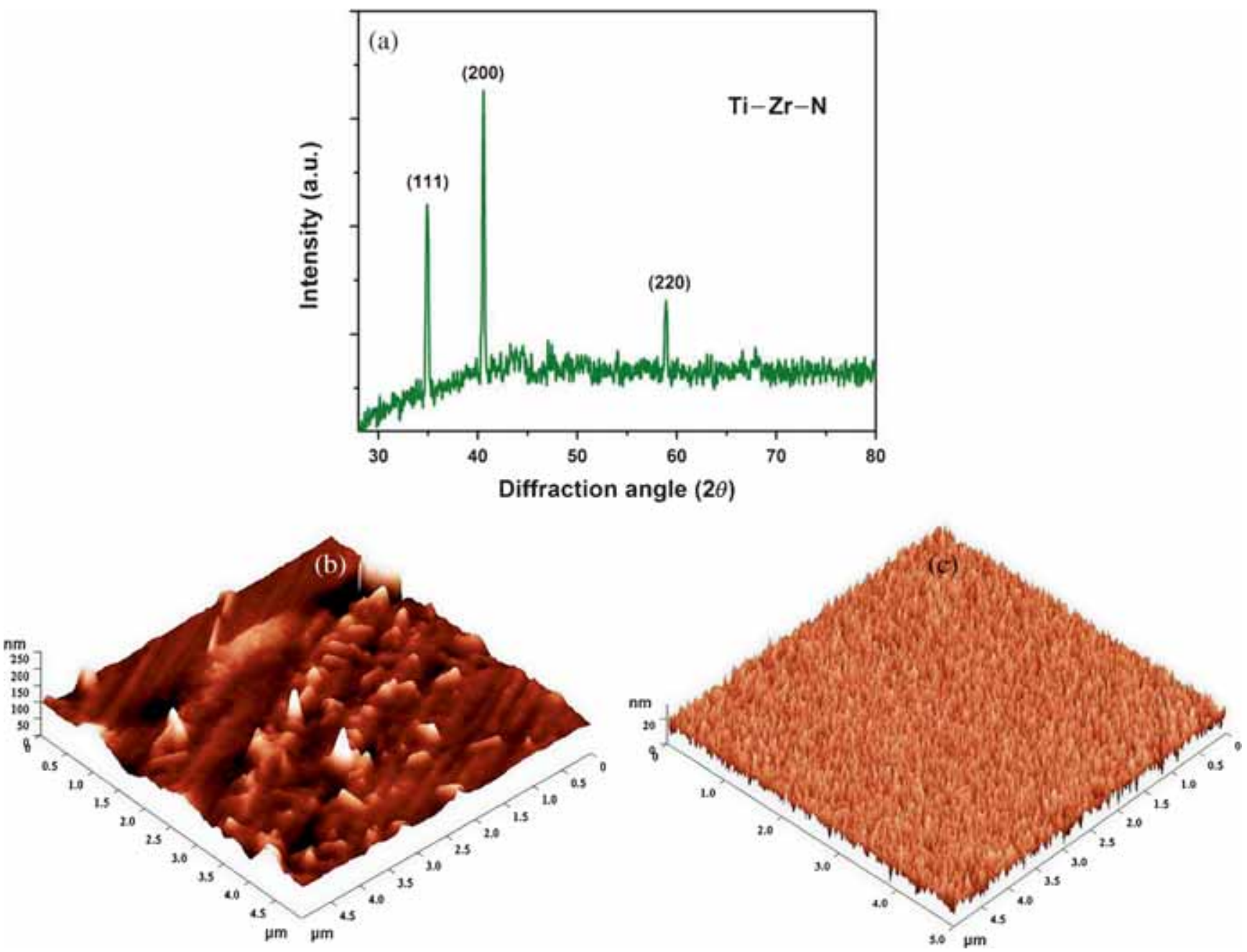

Figure 1. (a) GIXRD pattern of TiZrN coatings. (b) AFM images of uncoated 316L SS and (c) TiZrN coatings. 
volunteers by venipuncture into sterile tubes containing $3.8 \%$ (wt/vol) trisodium citrate and gently mixed. Whole blood centrifugation was done at 800 cycles $\mathrm{min}^{-1}$ for 10 min at $37^{\circ} \mathrm{C}$ to extract platelets. Then the highly concentrated platelets were compromised with homologous solution to acquire 330 platelets $\mathrm{mm}^{-3}$ and exposed on the test samples for $2 \mathrm{~h}$. Finally, samples were gently washed with PBS solution and stained with $\mathrm{AO}$ for epifluorescence micrograph.

\subsection{Electrochemical studies}

The electrochemical test was carried out at room temperature in artificial blood plasma according to PN-EN ISO 10993-15 standard $\left(\mathrm{g} \mathrm{l}^{-1}\right)$ was $\mathrm{NaCl} 6.8, \mathrm{CaCl}_{2} 0.200, \mathrm{KCl}$ $0.4, \mathrm{MgSO}_{4}$ 0.1, $\mathrm{NaHCO}_{3} 2.2, \mathrm{Na}_{2} \mathrm{HPO}_{4}$ 0.126, $\mathrm{NaH}_{2} \mathrm{PO}_{4}$ 0.026. All measurements were conducted in standard threeelectrode cell configurations with $1 \mathrm{~cm}^{2}$ exposed area. In order to establish the open-circuit potential (OCP), samples were immersed in solution for about $60 \mathrm{~min}$. After attaining the steady state, the potentiodynamic polarization studies were carried out at a scan rate of $10 \mathrm{mV} \mathrm{s}^{-1}$. The corrosion potential $\left(E_{\text {corr }}\right)$, current density $\left(I_{\text {corr }}\right)$, corrosion rate were evaluated from the Tafel plot. The electrochemical impedance spectroscopy (EIS) measurement was observed in the frequency range of $0.1 \mathrm{~Hz}-100 \mathrm{kHz}$ with an opencircuit potential and alternating current (AC) amplitude of 10 $\mathrm{mV}$.

\section{Result and discussion}

Figure 1a shows the XRD pattern of TiZrN coating on $316 \mathrm{~L}$ $\mathrm{SS}$. The peaks at $2 \theta$ value of $34.9^{\circ}, 40.5^{\circ}$ and $58.9^{\circ}$ corresponded to the (111), (200) and (220) planes of cubic TiZrN which is in good agreement with standard JCPDS card no. 89-5214. Figure $1 \mathrm{~b}$ and $\mathrm{c}$ shows the AFM surface images of the uncoated 316L SS and TiZrN films, respectively. Compared to uncoated substrate (figure 1b), the TiZrN (figure 1c) coatings displayed smooth surface with evenly distributed

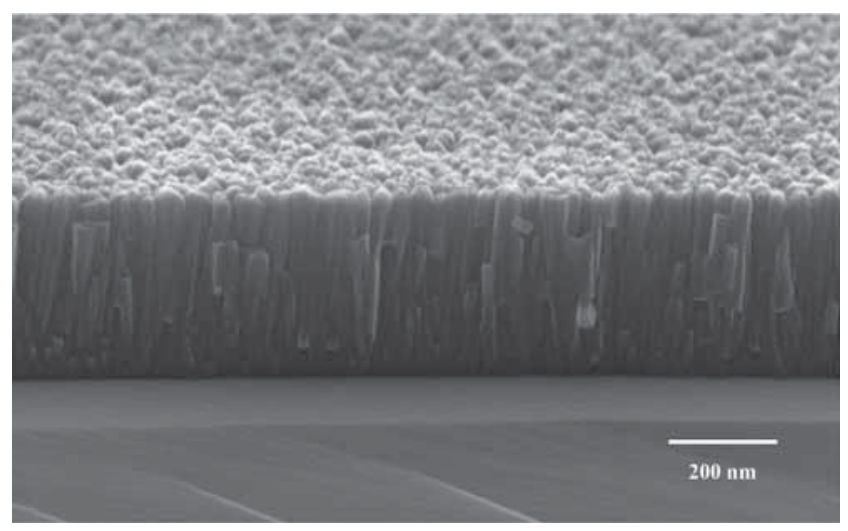

Figure 2. SEM images of cross-sectional view of TiZrN-coated 316L SS. grains. The calculated roughness $(\mathrm{Ra})$ and root mean square (RMS) value of the uncoated 316L SS was 4.38 and $13.37 \mathrm{~nm}$, whereas TiZrN coatings showed 3.535 and $8.44 \mathrm{~nm}$. Figure 2 shows the cross-sectional analysis of TiZrN-coated 316L SS. Cross-sectional view clearly reveals the columnar growth of the films with closely packed grains which is well agreed with AFM results. The film thickness was found to be $350 \mathrm{~nm}$. Figure 3 shows the EDAX analysis to find chemical composition of corroded samples. The presence of $\mathrm{Ti}, \mathrm{Zr}, \mathrm{N}$ elements confirms the TiZrN coatings.

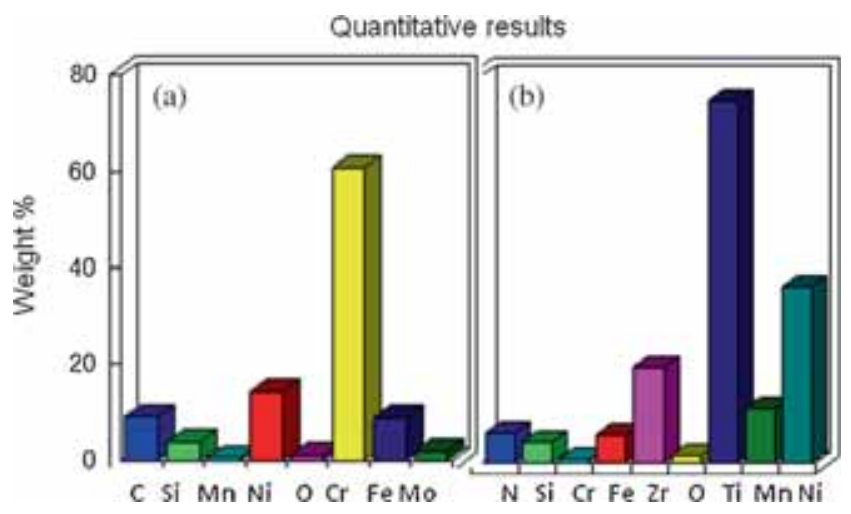

Figure 3. Elemental analysis of uncoated 316L SS and TiZrN coating.
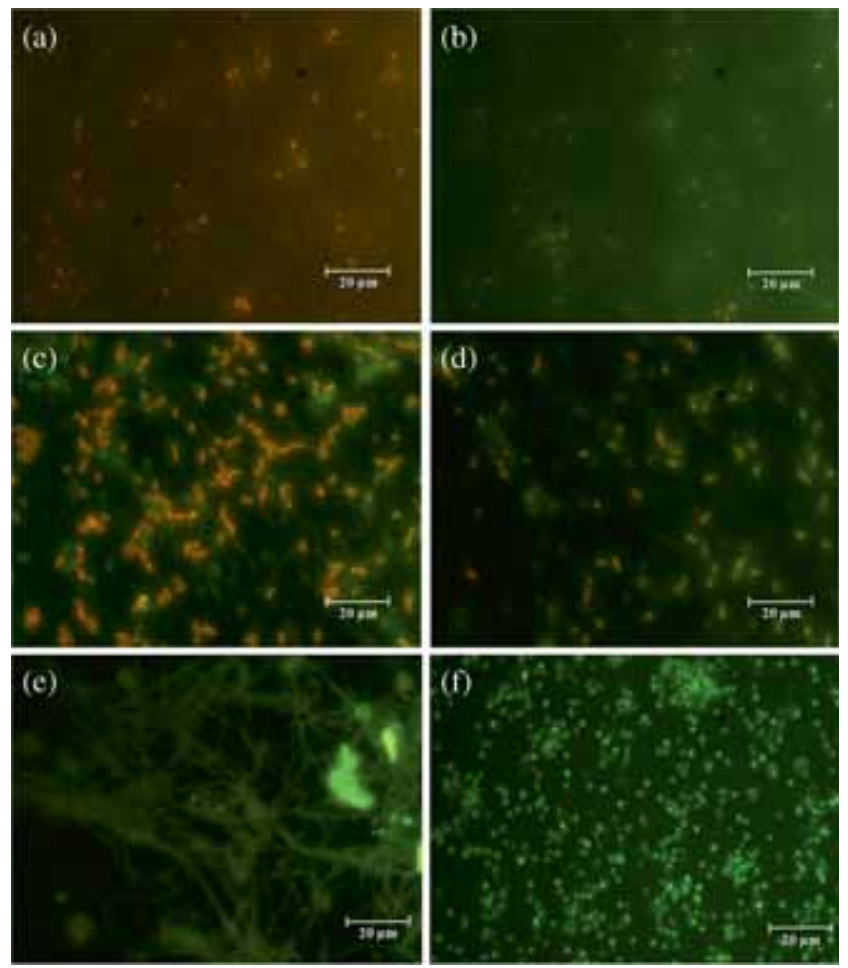

Figure 4. Epifluorescence images of bacterial invasion on uncoated 316L SS (for (a) Gram (+)ve and (b) Gram (-)ve, respectively) and TiZrN coatings (for (b) Gram (+)ve and (d) Gram (-)ve); and platelets adhesion for (e) uncoated 316L SS and (f) $\mathrm{TiZrN}$ coating. 
TVC analysis study exhibited very less bacterial adhesion onto TiZrN-coated substrate than uncoated 316L SS, which is due to the lower surface roughness. From the observation, more E. coli bacteria were seen than $S$. aureus bacteria on both uncoated and coated samples owing to higher surface area of E. coli bacteria. This is because it possess higher adhesion than Gram (+)ve bacteria. ${ }^{8}$ The TVC for the $S$. aureus and E. coli bacteria was found to be $1.60 \times 10^{1}$, 75 and $2.75 \times 10^{2}, 1.07 \times 10^{1}$ for uncoated 316L SS and TiZrN, respectively. Epifluorescence microscopy indicates the antimicrobial efficiency of coated and uncoated 316L SS. Figure $4 \mathrm{a}$ and $\mathrm{b}$ and $\mathrm{c}$ and $\mathrm{d}$ indicate $S$. aureus and $E$. coli bacteria, respectively. Results reveal that (figure $4 \mathrm{~b}$ and d) poor microbial efficiency has been found on both coated as well as uncoated specimens.

Antimicrobial activity of TiZrN and uncoated 316L SS were evaluated by epifluorescence microscopy analysis (calculated date not shown). Uncoated 316L SS exhibits $2 \%$ (figure 4a) of microbial efficiency against $S$. aureus and exhibits 3\% (figure 4c) against E. coli. Whereas, TiZrN coating shows antibacterial activity is about 3\% (figure $3 \mathrm{~b}$ ) against $S$. aureus and exhibits 5\% (figure 4d) against E. coli. Similarly, results clearly reveal the poor antibacterial effect of both TiZrN as well as uncoated 316L SS substrate.

To verify the haemocompatibility of test samples, platelets adhesion and activation in human blood were tested. The samples used in the platelets activation test were qualitatively examined by epifluorescence microscopy.

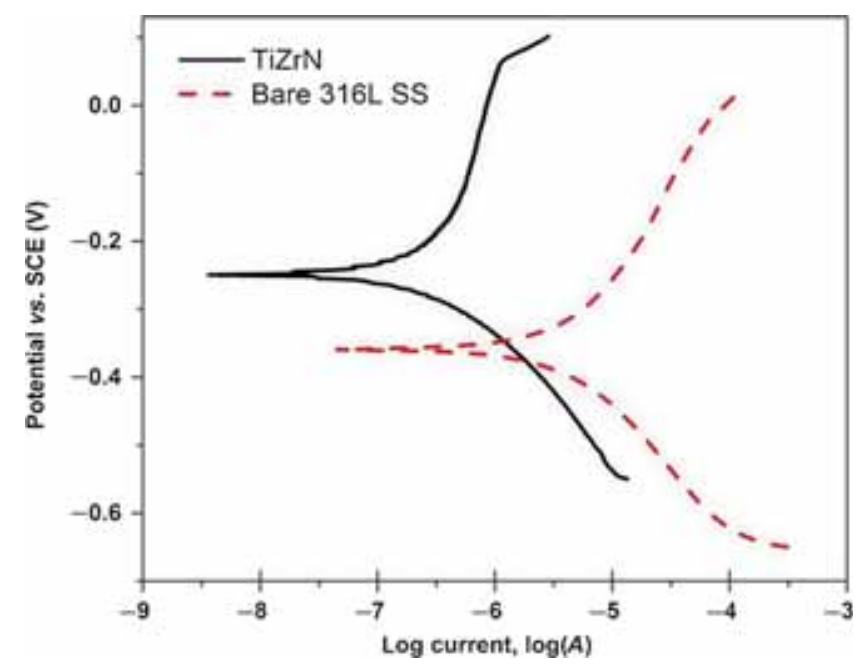

Figure 5. Potentiodynamic polarization curves of uncoated $316 \mathrm{~L}$ SS and TiZrN coating.
Results indicate that platelets adherence with pseudopods was observed in uncoated 316L SS (figure 4e) which are typical for platelets in activated states. ${ }^{9,10}$ According to the value for RMS roughness, uncoated samples exhibited larger roughness value. Hence, these irregular surface and higher RMS value enhanced the fibrinogen activity, thereby clotting cascade effect formed on the surface. TiZrN coating also showed the platelets adhesion (figure 4f). However, there was not much platelet activation seen in the coated sample, which might be due to very less RMS value and higher surface smoothness along with superior haemocompatibility nature of TiZrN. The TiZrN-coated 316L SS exhibits high haemocompatibility nature, platelets were seen with disc shapes. ${ }^{11}$

The potentiodynamic polarization curves of uncoated 316L SS and TiZrN-coated sample are presented in figure 5. It can be seen from potentiodynamic polarization curves, the TiZrN coated sample showed higher corrosion potential $\left(E_{\text {corr }}\right)$ and lower corrosion current density $\left(I_{\text {corr }}\right)$ than the uncoated sample, demonstrating that the TiZrN significantly increases the corrosion resistance of the $316 \mathrm{~L}$ SS substrate are given in table 1 . From the polarization test results, the protective efficiency, $P_{\mathrm{i}}(\%)$ of the film can be calculated by

$$
P_{\mathrm{i}}(\%)=\left[1-\left(I_{\text {corr }}\right)\right] \text {. }
$$

Uncoated 316L SS exhibited poor corrosion protection efficiency in artificial blood plasma than that of TiZrN coating. Figure 6 shows the morphology of corroded samples. Large number of pits were seen in uncoated 316L SS substrate, which is a evidence for its poor corrosion resistance. It due to the interaction of metal substrates with aggressive ions (electrolyte solution) causes depassivation in the small area of metal substrate (pit and crack propogation) resulting, depletion of native oxide layer present on uncoated substrate which triggers electrochemical potential amidst pit and surrounding metal. This results dissolution of metal ions along with crack propagation ${ }^{12}$ (figure 6), promotes high corrosion
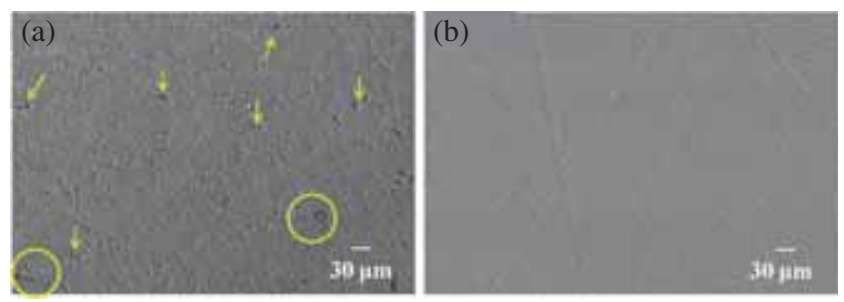

Figure 6. SEM images of uncoated 316L SS and TiZrN coating. (Note: Arrow indicates pits; circular indicates crack propagation).

Table 1. Potentiodynamic polarization and EIS data of test samples in ABP solution.

\begin{tabular}{lcccrrc}
\hline Samples & $\begin{array}{c}E_{\text {corr }} \\
(\mathrm{V})\end{array}$ & $\begin{array}{c}I_{\text {corr }} \\
\left(\mathrm{nA} \mathrm{cm}^{-2}\right)\end{array}$ & $\begin{array}{c}\text { Corrosion rate } \\
\left(\times 10^{-3} \mathrm{~mm} \mathrm{yr}^{-1}\right)\end{array}$ & $\begin{array}{c}R_{\mathrm{ct}} \\
\left(\mathrm{k} \Omega \mathrm{cm}^{2}\right)\end{array}$ & $\begin{array}{c}C_{\mathrm{dl}} \\
\left(\mathrm{nF} \mathrm{cm}^{-2}\right)\end{array}$ & $\begin{array}{c}P_{\mathrm{i}} \\
(\%)\end{array}$ \\
\hline 316L SS & -0.362 & 171.0 & 1.985 & 4.48 & 15.96 & - \\
TiZrN & -0.237 & 34.1 & 0.396 & 46.69 & 0.14 & 80.01 \\
\hline
\end{tabular}


current density, whereas, corrosion protection efficiency has increased upto $80 \%$ in TiZrN coating. When co-sputtering was in progress, $\mathrm{Ti}$ as well as $\mathrm{Zr}$ ions will react with nitrogen and get deposited onto the substrate at high temperature which cause high mobility and leads higher dense with compact grains distribution favours defect and pinhole free film. Further, this dense film protects the corrosive ions penetration through the film surfaces, thereby anodic current was drastically decreased.

In order to further provide the information on the corrosion inhibition effect of uncoated and coated samples, electrochemical impedance spectroscopy was carried out to examine the corrosion resistance. From the Nyquist plots (figure is not shown), it is observed that the increase in charge transfer resistance $\left(R_{\mathrm{ct}}\right)\left(46.69 \mathrm{k} \Omega \mathrm{cm}^{2}\right)$ and decrease in double layer capacitance $\left(C_{\mathrm{dl}}\right)\left(0.14 \mathrm{nF} \mathrm{cm}^{-2}\right)$ for TiZrN coated sample than uncoated 316L SS (table 1), indicates the corrosion inhibition efficiency of coated sample. This result suggests that the TiZrN coatings have anticorrosion as well as biocompatibility properties that are beneficial for bioimplant applications.

\section{Conclusions}

TiZrN coating was deposited by reactive magnetron cosputtering. Crystallinity and surface topography were studied by XRD and AFM analysis. From the present investigation, it has been concluded that TiZrN coating exhibited very less bacterial adhesion against Gram $(+)$ ve bacteria and Gram (-)ve, better haemocompatibility nature and superior corrosion resistance than the uncoated 316L SS. Therefore, it is implicated that TiZrN surface modified $316 \mathrm{~L} \mathrm{SS}$ is an ideal candidature in order to make long-term implantsurvival as well as better biocompatibility nature for bioimplant applications.

\section{Acknowledgements}

We thank Dr Jeppiaar, Chancellor of Sathyabama University, Chennai, for his motivation and financial assistance.

\section{References}

1. Scarano A, Piattelli M, Vrespa G, Caputi S and Piattelli A 2003 J. Oral Implant. 2980

2. Huang J-H, Yang H-C, Guo X-J and Yu G-P 2005 Surf. Coat. Technol. 195204

3. Tung H-M, Huang J-H, Tsai D-G, Ai C-F and Yu G-P 2009 Mater. Sci. Eng. A $\mathbf{5 0 0} 104$

4. Zhang G-P, Wang X-Q, Lu G-H, Zhou L, Huang J, Chen W and Yang S-Z 2013 Chin. Phys. B 22035204

5. Niu E W, Li L, Lv G H, Chen H, Feng W R, Fan S H, Yang S Z and Yang X Z 2007 Mater. Sci. Eng.: A 460135

6. Subramanian B, Ananthakumar R and Jayachandran M 2010 Vacuum 85601

7. Hodak S K, Seppanen T and Tungasmita S 2008 Solid State Phenom. 136133

8. Chawla V, Jayaganthan R, Chawla A K and Chandra R 2008 Mater. Chem. Phys. 111414

9. Subramanian B, Dhandapani P, Maruthamuthu S and Jayachandran M 2012 J. Biomater. Appl. 26687

10. Escobar D, Ospina R, Gomez A G, Restrepo-Parra E and Arango P J 2014 Mater. Charact. 88119

11. Habibi M, Liem P, Luong W and Netchaeva E 2009 J. Exp. Microbiol. Immunol. 1375

12. Kamachi Mudali U, Sridhar T M and Raj B 2003 Sadhana 28 601 